\title{
Evaluation of Positive Predictive Value for Digital Panoramic Radiography in Comparison to Ultrasound in the Diagnosis of Calcified Carotid Atheroma
}

\author{
Fatemeh Ezoddini-Ardakani ${ }^{*}$, Maryam Mirzaei², Saman Nayer ${ }^{3}$, Sajad Besharati ${ }^{4}$, \\ Malihe Moeini ${ }^{5}$ \\ ${ }^{1}$ Department of Oral and Maxillofacial of Radiology, Faculty of Dentistry, Shahid Sadoughi University of \\ Medical Sciences, Yazd, Iran \\ ${ }^{2}$ Faculty of Dentistry, Shahid Sadoughi University of Medical Sciences, Yazd, Iran \\ ${ }^{3}$ Department of Oral and Maxillofacial of Radiology, Faculty of Dentistry, Alborz, Iran \\ ${ }^{4}$ Shahid Beheshti University of Medical Sciences, Tehran, Iran \\ ${ }^{5}$ Shahid Sadoughi University of Medical sciences, Yazd, Iran \\ Email: ${ }^{*}$ ezoddini@gamil.com
}

Received 4 June 2014; revised 20 July 2014; accepted 2 August 2014

Copyright (C) 2014 by authors and Scientific Research Publishing Inc.

This work is licensed under the Creative Commons Attribution International License (CC BY).

http://creativecommons.org/licenses/by/4.0/

c) (i) Open Access

\begin{abstract}
Aim: Detection of calcified carotid atheroma (CCA) has an important role in reducing the incidence of Cerebro Vascular Accident (CVA). The aim of this study was to evaluate efficacy of panoramic digital radiography in detecting atherosclerosis. Methods: It is descriptive-analytical diagnostic study. The people (22 to 62 years old) were referred to a radiology clinic to perform panoramic radiography for diagnosis of CCA. Individuals who were suspected were introduced to the radiology department of dental school to undergo ultrasound evaluation to CCA. For the 41 patients (55 sides), ultrasound was performed. For data analysis, the Chi-square and Fisher's exact test were used. Results: The prevalence of CCA was $2.43 \%$. The PPV of digital panoramic was $45.5 \%$. There was no significant relationship between age $(P=0.14)$ and sex $(P=0.539)$ and $P P V$ of digital panoramic. The PPV of digital panoramic was significantly associated with hypertension $(P=0.032)$. Conclusion: It seems that panoramic can be used to screen patients with a history of hypertension for atherosclerosis.
\end{abstract}

\section{Keywords}

Radiography, Panoramic, Digital, Ultrasonography, Atherosclerosis

\footnotetext{
${ }^{*}$ Corresponding author.
}

How to cite this paper: Ezoddini-Ardakani, F., Mirzaei, M., Nayer, S., Besharati, S. and Moeini, M. (2014) Evaluation of Positive Predictive Value for Digital Panoramic Radiography in Comparison to Ultrasound in the Diagnosis of Calcified Carotid Atheroma. Health, 6, 1933-1940. http://dx.doi.org/10.4236/health.2014.615226 


\section{Introduction}

Atherosclerosis is the leading cause of death in developed countries. It can induce a temporary ischemic attack or a complete stroke in the arteries that supply the brain and central nervous system (CNS). Atherosclerosis in cerebrovascular circulation preferably affects the bifurcation of carotid artery [1].

Occasionally, some parts of the atherosclerotic lesions are calcified and become visible on conventional panoramic radiography [2]. Atheroma may be observed as a radiopaque nodular mass in the bifurcation of carotid artery or as two radiopaque vertical lines in the vessel wall in the lower edge of the third cervical vertebra [3]. Calcified carotid atheroma in many individuals is symptomless but in others the first clinical sign is usually a stroke [4].

Production of atheroma is increased in conditions such as dyslipidemia, hypertension, smoking, old inflammations, immune responses, autoimmune disorders and diabetes mellitus. Its prevalence is also higher in males than females and in the latter case, it will increase after menopause [5]. Calcified carotid atheroma resembles some anatomical structures such as the hyoid bone, styloid process, thyroid cartilage, epiglottis, and should be differentiated from calcification of stylohyoid and stylomandibular ligaments, tonsilolithiasis, venous calcification, calcified lymphatic nodes and anterior tubercle of the atlas [6].

In 1980, researchers discovered calcified carotid atheroma on panoramic radiographs of patients and introduced a screening procedure [7] [8]. On panoramic radiography, carotid artery calcification can be seen in mandibular angle, in the soft tissue surrounding the spine between vertebrae C3-C4 [9].

All panoramic radiographs, particularly in high risk patients, should be evaluated for possible carotid artery calcification by dentists [10].

Ultrasonography is a real-time technique which produces images without the use of ionizing radiation. Ultrasonography uses waves with the frequency greater than $20 \mathrm{kHz}$ which is more than the human's hearing range [11].

Carotid ultrasonography is a non-invasive method for detecting calcified atheroma [12] and now it is the preferred method to evaluate carotid artery stenosis [13].

Pornprasertsuk and colleagues in a study on 85 patients with metabolic syndrome evaluated panoramic radiography and ultrasonography in the diagnosis of calcified carotid plaque. They found sensitivity $=42.19 \%$, specificity $=97.17 \%$, positive predictive value $(\mathrm{PPV})=90 \%$, and negative predictive value $(\mathrm{NPV})=73.57 \%$ for panoramic radiography in comparison to ultrasonography. From 170 cervical sonographies, 37 calcified plaques, and 9 non-calcified plaques were not detected by panoramic radiography [14].

Alzoma et al. studied panoramic radiographs from 555 patients aged 30 years or more. In 28 cases (5\%), panoramic radiography showed calcified carotid atheroma, from which 21 (75.3\%) were observed in males and 7 (25.1\%) in females [15].

The aim of this study was to evaluate the efficacy of digital panoramic radiography for detection of calcified carotid atheroma.

\section{Materials and Methods}

This was a diagnostic tests study conducted on 41 patients. Digital panoramic radiographs were taken by a technician in a maxillofacial radiology center with a digital device (Planmeca 2002 EC Proline, CR Model 110 Regius manufacturers, Konica Minolta Japan) under following conditions: $80 \mathrm{KVP}, 12 \mathrm{MA}$ and 18 seconds). The patients referred to the oral radiology ward of the dental faculty from October 2011 to June 2012, entered the study and those with low-quality radiographs were excluded from the study. An informed consent was obtained from all participants.

The digital panoramic radiographs were studied, by changing the contrast and brightness to observe the atheroma radiopaque masses.

Calcified carotid atheroma is revealed as a radiopaque nodular mass or two radiopaque vertical lines in the soft tissues of the neck at the level of the lower edge of C3 vertebra in one or both sides [3].

It can be observed below or above the hyoid bone [3] and $1.5-4 \mathrm{~cm}$ below and at the posterior region of the mandibular angle [5] (Figure 1).

After detection of calcified carotid atheroma by an oro-maxillofacial radiologist, patients were informed about it and after obtaining written informed consent, they were referred to oro-maxillofacial radiology ward, faculty of dentistry, Yazd, Iran for sonography.

A questionnaire asking information on age, gender, menopausal status (in females), background diseases (hypertension, diabetes, and elevated cholesterol), smoking, and alcohol consumption was filled for each participant. 

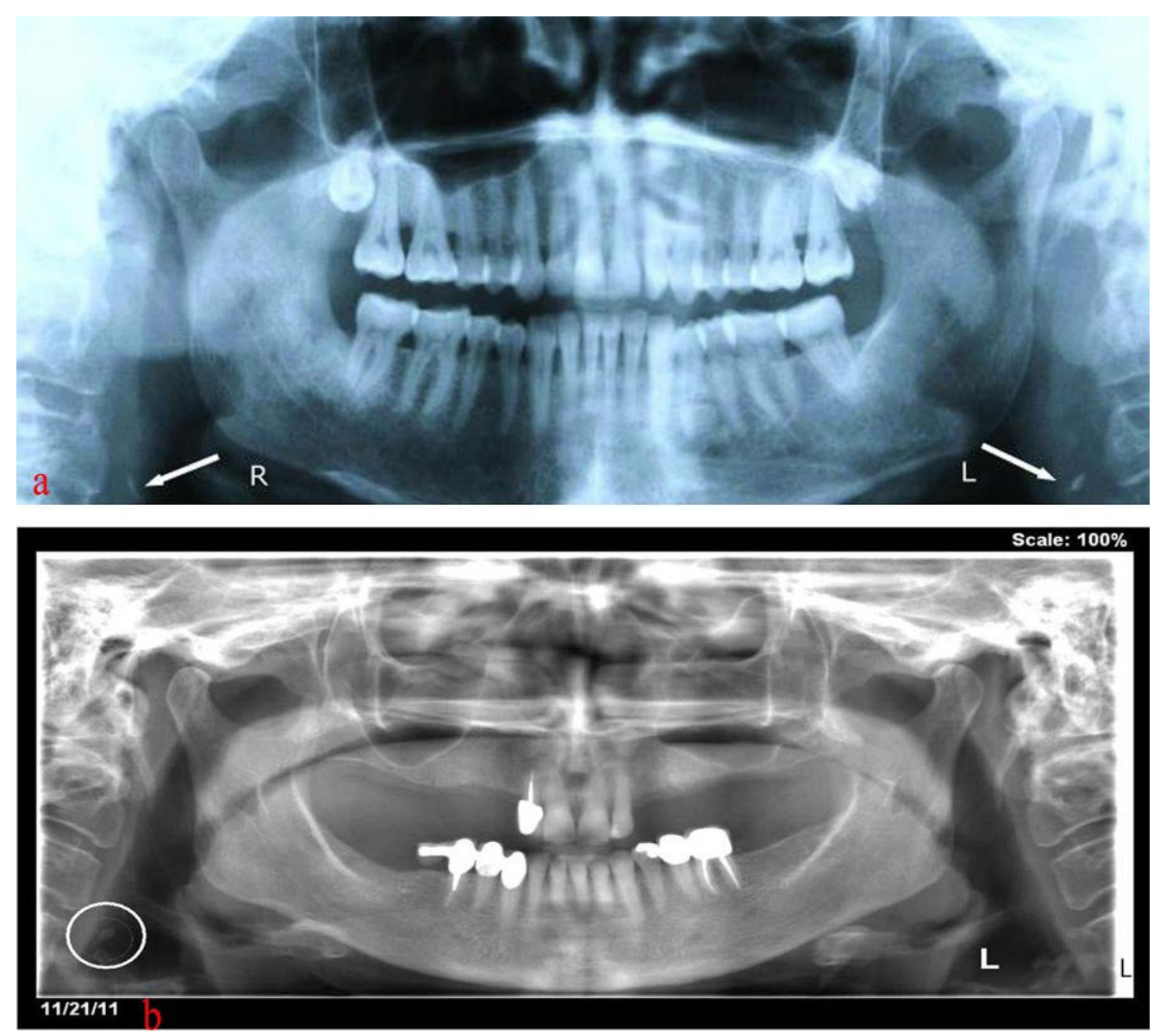

Figure 1. (a) Bilateral calcified carotid atheroma; (b) Unilateral calcified carotid atheroma.

Ultrasound study was done in the radiology department by an oro-maxillofacial radiologist (device: Honda HS-4000, Honda Electronic, Toyohashi, Japan).

For ultrasonography, carotid pulse was palpated $2.5 \mathrm{~cm}$ below and $1.5 \mathrm{~cm}$ posterior to the mandibular angle. Then transparent gel was applied on the area. Transducer moved above the level of the thyroid gland to the level of the carotid artery bifurcation and then a little to the posterior and anterior parts to obtain sections from internal and external carotid arteries. The transducer was moved in both vertical and horizontal directions to prepare longitudinal sections with the frequency of $10 \mathrm{MHz}$.

Calcified carotid atheroma was seen as an area of dense hyper-echoic region with acoustic shadowing that was placed $2.5 \mathrm{~cm}$ below and $1.5 \mathrm{~cm}$ above the carotid artery bifurcation.

Copies of all results of ultrasonography were examined by a general and an oro-maxillofacial radiologist for detection of atheroma and the results were recorded on a separate form. Patients with documented calcified carotid atheroma were referred to a neurologist for further evaluations.

The study was approved by the ethics committee of Shahid Sadoughi University of Medical Sciences under code number 134730.

After data collection, data was coded and analyzed by SPSS software (ver. 17). Fisher exact and Chi-square tests were used to determine the relationship between qualitative variables.

\section{Results}

In total, 1682 digital panoramic radiographs were evaluated and calcified carotid atheroma was observed in 2.43\% of cases; so the study was conducted on 41 patients (16 males and 27 females) aged 22 - 67 years old (mean: $45.13 \pm 11.5$ years) with calcified carotid atheromas detected in digital panoramic radiographs. Among these patients, 14 women showed bilateral atheromas and 27 patients revealed unilateral atheromas in digital panoramic 
radiography. Participants with bilateral atheromas were considered as two samples, so 55 samples with 35 atheromas in males and 20 in females were studied. Ultrasonography (US) confirmed the diagnosis of carotid atheroma.

In 14 patients with bilateral atheromas in panoramic digital radiography, US showed 5 patients (35.7\%) with bilateral atheromas, 3 (21.4\%) unilateral atheromas and 6 (42.8\%) without atheromas.

In 27 patients with unilateral atheromas in digital panoramic radiographs, US showed unilateral atheromas in 12 (44.44\%) cases and 15 (55.56\%) revealed no evidence of calcified carotid atheroma.

In this study, the Gold standard method was ultrasound technique, and $45.5 \%$ of the patients revealed calcified carotid atheromas (PPV $=45.5 \%$ ). There were $54.5 \%$ false negative diagnoses by digital panoramic radiography compared to US.

The frequency of calcified carotid atheromas was $45.5 \%$ (in males: $40 \%$, in females: $48.6 \%$ ). Table 1 and Table 2 show the frequency distribution of atheromas in different genders and ages respectively. The difference in the frequency regarding gender and age was not significant ( $\mathrm{P}=0.539$ for gender, $\mathrm{P}=0.14$ for age).

Detection of atheroma in diabetic patients (66.7\%) was more than non-diabetics (41.3\%). Fisher's exact test showed no significant difference between diabetics and non-diabetics regarding the frequency of atheromas $(\mathrm{P}=$ 0.273) (Table 3).

Table 4 shows the frequency distribution of atheromas in individuals with high cholesterol and normal cholesterol levels. Relationship between elevated levels of blood cholesterol with atheroma with Fisher's exact test was not significant $(\mathrm{P}=1.00)$.

Hypertension showed a significant relationship with the presence of atheromas $(\mathrm{P}=0.032)$. Table 5 shows this relationship.

The frequency of atheromas was higher among post-menopausal women than premenopausal ones but the difference was not statistically significant $(\mathrm{P}=0.101)$ (Table 6).

Table 1. Gender distribution of calcified carotid atheroma detection in samples examined by ultrasound technique.

\begin{tabular}{ccccccccc}
\hline \multirow{3}{*}{ Gender } & \multirow{2}{*}{ Atheroma } & \multicolumn{2}{c}{ Yes } & \multicolumn{2}{c}{ No } & \multicolumn{2}{c}{ Total } \\
\cline { 3 - 8 } & & $\mathbf{N}$ & $\mathbf{\%}$ & $\mathbf{N}$ & $\mathbf{\%}$ & $\mathbf{N}$ & $\%$ \\
\hline & F & 17 & 48.6 & 18 & 51.4 & 35 & 100 \\
& M & 8 & 40 & 12 & 60 & 20 & 100 \\
& Total & 25 & 45.5 & 30 & 54.5 & 55 & 100 \\
\hline
\end{tabular}

Table 2. Age distribution of calcified carotid atheroma detection in samples by US.

\begin{tabular}{|c|c|c|c|c|c|c|c|c|}
\hline \multirow[b]{2}{*}{ Age (Year) } & \multirow{2}{*}{\multicolumn{2}{|c|}{ Atheroma }} & \multicolumn{2}{|c|}{ Yes } & \multicolumn{2}{|c|}{ No } & \multicolumn{2}{|c|}{ Total } \\
\hline & & & $\mathbf{N}$ & $\%$ & $\mathbf{N}$ & $\%$ & $\mathbf{N}$ & $\%$ \\
\hline & $22-49$ & & 10 & 35.7 & 18 & 64.3 & 28 & 100 \\
\hline & 50 - 62 & & 15 & 55.6 & 12 & 44.4 & 27 & 100 \\
\hline & Total & & 25 & 45.5 & 30 & 54.5 & 55 & 100 \\
\hline
\end{tabular}

Table 3. Distribution of calcified carotid atheroma detection in ultrasound technique in diabetic and non-diabetic patients.

\begin{tabular}{|c|c|c|c|c|c|c|}
\hline \multirow{2}{*}{ Diabetes Status } & \multicolumn{2}{|c|}{ Yes } & \multicolumn{2}{|c|}{ No } & \multicolumn{2}{|c|}{ Total } \\
\hline & $\mathbf{N}$ & $\%$ & $\mathbf{N}$ & $\%$ & $\mathbf{N}$ & $\%$ \\
\hline Diabetics & 6 & 66.7 & 3 & 33.3 & 9 & 100 \\
\hline Non Diabetics & 19 & 41.3 & 27 & 58.7 & 46 & 100 \\
\hline Total & 25 & 45.5 & 30 & 54.5 & 55 & 100 \\
\hline
\end{tabular}


Table 4. Distribution of calcified carotid atheroma detection with ultrasound in patients with high cholesterol compared with patients with normal blood cholesterol levels.

\begin{tabular}{cccccccc}
\hline \multirow{2}{*}{ Blood Cholesterol } & \multicolumn{2}{c}{ Ytheroma } & \multicolumn{2}{c}{ Yes } & \multicolumn{2}{c}{ Total } \\
\cline { 2 - 8 } & $\mathbf{N}$ & $\mathbf{\%}$ & $\mathbf{N}$ & $\mathbf{\%}$ & $\mathbf{N}$ & $\%$ \\
\hline High Cholesterol & 4 & 50 & 4 & 50 & 8 & 100 \\
Normal Cholesterol & 21 & 44.7 & 26 & 55.3 & 47 & 100 \\
Total & 25 & 45.5 & 30 & 54.5 & 55 & 100 \\
\hline
\end{tabular}

Table 5. Distribution of calcified carotid atheroma detection by ultrasound in patients with hypertension and patients with normal blood pressure.

\begin{tabular}{cccccccccc}
\hline \multirow{3}{*}{ Blood Pressure } & \multirow{2}{*}{ Atheroma } & \multicolumn{2}{c}{ Yes } & \multicolumn{2}{c}{ No } & \multicolumn{2}{c}{ Total } \\
\cline { 3 - 9 } & & $\mathbf{N}$ & $\mathbf{\%}$ & $\mathbf{N}$ & $\mathbf{\%}$ & $\mathbf{N}$ & $\%$ \\
\hline & High & 8 & 80 & 2 & 20 & 10 & 100 \\
& Normal & 17 & 37.8 & 28 & 62.2 & 45 & 100 \\
& Total & 25 & 45.5 & 30 & 54.5 & 55 & 100 \\
\hline
\end{tabular}

Table 6. Distribution of calcified carotid atheroma detection by ultrasound based on the menopause status of the female patients.

\begin{tabular}{cccccccc}
\hline \multirow{2}{*}{ Atheroma } & \multicolumn{2}{c}{ Yes } & \multicolumn{2}{c}{ No } & \multicolumn{2}{c}{ Total } \\
\cline { 2 - 8 } Menopause Status & $\mathbf{N}$ & $\mathbf{\%}$ & $\mathbf{N}$ & $\mathbf{\%}$ & $\mathbf{N}$ & $\%$ \\
\hline Menopause & 9 & 64.3 & 5 & 35.7 & 14 & 100 \\
Non Menopause & 8 & 38.1 & 13 & 61.9 & 21 & 100 \\
Total & 17 & 48.6 & 18 & 51.4 & 35 & 100 \\
\hline
\end{tabular}

\section{Discussion}

The most common cause of cerebrovascular accidents is the embolism from the carotid bifurcation and the internal carotid artery atheromas which causes blockage of arteries in the brain [16] [17]. Since 1981, numerous studies have shown that calcified atherosclerotic lesions in the carotid bifurcation are observed in panoramic radiography [18]-[21].

The prevalence of calcified carotid atheromas on panoramic digital radiography in this study was $2.43 \%$ which was somewhat similar to some other studies, e.g. 2\% in Friedlander et al. in 1981 [19], 3\% in Friedlander AH study in 1994 [22], 3\% - 5\% in Friedlander AH in 2001 [23], 2\% - 5\% in Tarim Ertas et al. [9], 5\% in Ohbata et al. [24], 3.6\% in Carter et al. study [25]. This similarity is probably due to the same number and type of samples of panoramic radiographs.

Beckstrom reported that $24 \%$ of patients with cancer of the head and neck area, and $20 \%-35 \%$ of patients with type 2 diabetes mellitus showed calcified carotid atheromas [26], although their subjects were selected from patients with atherogenic risk factors. Friedlander studied panoramic radiographs of 61 patients aged 41 77 years (mean age: 60.5 years) who had undergone radiotherapy 36 months prior to the study and 61 cases were considered as the control group. Prevalence of atheroma in the group that had radiotherapy was $27.9 \%$ which is close to the results of Beckstrom and in control group was $4.9 \%$, somewhat similar to the results of this study [27].

Friedlander in a study on panoramic radiographs of 52 women, with mean age of 70.4 years and with a more than 12 months of menstrual cessation found calcified atheromas in about 31\% of cases.

Our study was conducted on both men and women and the average age was $45.13 \pm 11.5$ years and among 35 atheromas in women, there were only 14 postmenopausal cases. Older age and menopause are two important risk factors for atherosclerotic diseases. So the higher prevalence of calcified carotid atheromas in the above mentioned study versus our study is probably due to this reason (2.43\% versus $31 \%)$ [18].

Joakimson et al.' study was conducted on 2588 postmenopausal women and calcified carotid atheromas were seen in $49 \%$ of patients by ultrasonography [28]. 
In the ultrasound evaluation, even lesions without calcification can be detected, but panoramic approach can detect only calcified lesions. Also carotid artery atheromas which are not located in the focal trough of panoramic image are not visible in these images. There was a large difference between the results of Joakimsen and the present study (49\% versus $2.43 \%$ ), although they used ultrasonography for detection of atheromas but we used panoramic radiography.

B. Bayram et al. in a study assessed 4106 panoramic radiographs of patients $\geq 40$ years old and observed calcified carotid atheroma in 88 cases $(2.1 \%)$ which was consistent with the results of the present study. They found a PPV of $34.7 \%$ for panoramic radiography in detection of carotid atheromas. This measure in the study conducted by Ravon and Hollender, was 34.9\% [29].

Pornprasertstuk in a study on 85 patients with metabolic syndrome used panoramic radiography and ultrasonography for detection of carotid plaques. Thirty patients were detected to have calcified carotid plaques by panoramic radiography among whom 27 showed atheromas in ultrasonography, hence positive predictive value $=$ $90 \%$ [14].

Sisman examined panoramic radiographs of 1282 patients of more than 40 years of age, and found a higher prevalence of atheromas in women than men although the difference was not statistically significant [30]. This result is consistent with the results of our study.

Jonson, in his study on 117 patients with carotid calcified atheromas on panoramic radiography showed a significant relationship between gender and carotid artery stenosis $(\mathrm{P}=0.008)$ which was inconsistent with the results of our study [31].

Calcified carotid atheromas detected by ultrasonography were more common in women than men in 49 - 62 years age group, although the difference was not statistically significant. The frequency of these lesions was higher in diabetics, those with high cholesterol level, and postmenopausal women than non-diabetics, those with normal cholesterol level, and premenopausal women, respectively, although the differences were not statistically significant. The only significant association was observed with hypertension; therefore the panoramic digital radiography in patients with a history of high blood pressure can be used for screening of patients with carotid calcified atheroma.

Friedlander in 2011 found a significant association between increased blood pressure and atheroma which is consistent with the results of our study [32].

Also Friedlander in another study found hypertension in 94\% of patients with atheroma and increased blood cholesterol in $69 \%$ of them [33].

In this study, atheroma was observed in $80 \%$ of subjects with hypertension and $50 \%$ with hypercholesterolemia.

Studies, such as studies of Friedlander [1] [4] [8], Bayram [5], Henriques [23], Kamikawars [6], Ertas [9], Romano-sosa [34], Christou [35], Johansson [31] and Ezoddini [36], concluded that panoramic radiographs are useful in identifying patients with atheroma and dentists can play an important role in early detection of atheroma and prevention of its complications.

Finally, although the positive predictive value of digital panoramic radiography is medium, due to the low prevalence of calcification in the carotid and cost of ultrasonography and this fact that the interval between two visits of dentist routinely is 6 - 12 months, so dentists without bearing additional costs to patients can evaluate digital radiography in patients with a history of hypertension, and the suspected calcified carotid atheroma may refer to more efficient ways of diagnosis such as ultrasonography.

\section{Acknowledgements}

This study was fully funded by Shahid Sadoughi University of Medical Sciences in Yazd, Iran. Special thanks to Mr. Mohammad Hossein Ahmadieh for facilitating statistical analyses.

\section{References}

[1] Longo, D., Fauci, A., Kasper, D., Hauser, S., Jameson, J., et al. (2011) Harrison’s Principles of Internal Medicine. 18th Edition, McGraw-Hill Companies Inc., New York, 1077-1084.

[2] Manzi, F.R., Boscolo, F.N., de Almedia, S.M. and Haiterneto, F. (2003) Panoramic Radiography as an Auxillary in Detecting Patients at Risk for Cerebrovascular Accident (CVA): A Case Report. Journal of Oral Science, 45, 177-180. http://dx.doi.org/10.2334/josnusd.45.177 
[3] Friedlander, A.H. and Friedlander, I.K. (1996) Panoramic Dental Radiography: An Aid in Detecting Individuals Prone to Stroke. British Dental Journal, 181, 23-26. http://dx.doi.org/10.1038/sj.bdj.4809143

[4] Bayram, B., Uckan, S, Acikgoz, A., Muderrisoglu, H. and Aydinap, A. (2006) Digital Panoramic Radiography: A Reliable Method to Diagnose Carotid Artery Atheromas? Dentomaxillofacial Radiology, 35, 266-270. http://dx.doi.org/10.1259/dmfr/50195822

[5] Guimaraes Henriques, J.C., Kreich, E.M., Helena Baldani, M., Luciano, M., Cezar de Melocastilho, J., et al. (2011) Panoramic Radiography in the Diagnosis of Carotid Artery Atheromas and the Associated Risk Factor. Open Dentistry Journal, 5, 79-83. http://dx.doi.org/10.2174/1874210601105010079

[6] Kamikawa, R.S., Rereira, M.F., Fernandes, A. and Meurer, M.I. (2006) Study of the Localization of Radiopacities Similar to Calcified Carotid Atheroma by Means of Panoramic Radiography. Oral Surgery, Oral Medicine, Oral Pathology, Oral Radiology, and Endodontology, 101, 374-378. http://dx.doi.org/10.1016/j.tripleo.2005.03.030

[7] Drozdzowska, B., Pluskiewics, W. and Tarnawska, B. (2002) Panoramic Based Mandibular Indices in Relation to Mandibular Bone Mineral Density and Skeletal Status Assessed by Dual Energy x-Ray Absorptionometry and Quantitative Ultrasound. Dentomaxillofacial Radiology, 31, 361-367. http://dx.doi.org/10.1038/sj.dmfr.4600729

[8] Friedlander, A.H., Garrett, N.R., Chin, E.E. and Baker, J.D. (2005) Ultrasonographic Confirmation of Carotid Artery Atheromas Diagnosed via Panoramic Radiography. Journal of the American Dental Association, 136, 635-640. http://dx.doi.org/10.14219/jada.archive.2005.0235

[9] Ertas, E.T., Mavili, E., Sisman, Y., Sahman, H., Eto, Z.M., et al. (2010) Incidental Findings of Carotid Artery Stenosis Detected by Calcifications on Panoramic Radiographs: Report of Three Cases. Oral Radiology, 26, 116-127. http://dx.doi.org/10.1007/s11282-010-0047-4

[10] Tofanghchiha, M., Maryam, A., Mosallaei, S.S. and Moghaddam, M.A. (2009) Comparison of Panoramic Radiography in Detection of Carotid Artery Calcifications with Doppler Sonography Results. JQUMS, 13, 63-68.

[11] White, S.C. and Pharoah, M.J. (2009) Oral Radiology Principles and Interpretation. 6th Edition, Mosby, St. Louis, 175-190, 221-222.

[12] Arai, D., Yamaguchi, S., Murakami, M., Nakakuki, T., Fukuda, S., Satoh-Asahara, N., et al. (2011) Characteristics of Carotid Plaque Findings on Ultrasonography and Black Blood Magnetic Resonance Imaging in Comparison with Pathological Findings. Acta Neurochirurgica Supplementum, 112, 15-19. http://dx.doi.org/10.1007/978-3-7091-0661-7_3

[13] Forouzan-Nia, K.H., Nafisi-Moghadam, R., Abdollahi, M.H., Zare, S., Baradaran, S.H., et al. (2006) Carotid Artery Sonography Findings in 291 Patients Undergoing CABG. JSSU, 14, 15-22.

[14] Pornprasertsuk-Damrongsri, S., Virayavanich, W., Thanakun, S., Siriwonqpairat, P., Amaekchok, P., et al. (2011) Carotid Atheroma Detected by Panoramic Radiography and Ultrasonography in Patients with Metabolic Syndrome. Oral radiology, 27, 43-49. http://dx.doi.org/10.1007/s11282-011-0064-y

[15] Al-Zoman, H.A., Al-Sadhan, R.I., Al-Lahem, Z.H., Al-Sakakar, A.N. and Al-Fawaz, Y.F. (2012) Prevalence Carotid Calcification Detected on Panoramic Radiographs in a Soudi Population from a Training Institute in Central Saudi Arabia. Saudi Medical Journal, 33, 177-181.

[16] De Syo, D., Franjić, B.D., Lovričević, I., Vokelić, M. and Palenkić, H. (2005) Carotid Bifurcation Position and Branching Angle in Patients with Atherosclerotic Carotid Disease. Collegium Antropologicum, 29, 627-632.

[17] Warburton, L. and Gillard, J. (2006) Functional Imaging of Carotid Atheromatous Plaques. Journal of Neuroimaging, 16, 293-301. http://dx.doi.org/10.1111/j.1552-6569.2006.00045.x

[18] Friedlander, A.H. and Altman, L. (2001) Carotid Artery Atheromas in Postmenopausal Woman. Their Prevalence on Panoramic Radiographs and Their Relationship to Atherogenic Risk Factors. Journal of the American Dental Association, 132, 1130-1136. http://dx.doi.org/10.14219/jada.archive.2001.0340

[19] Friedlander, A.H. and Lande, A. (1981) Panoramic Radiographic Identification of Carotid Arterial Plaques. Oral Surgery, Oral Medicine, Oral Pathology, 52, 102-104. http://dx.doi.org/10.1016/0030-4220(81)90181-X

[20] Friedlander, A.H. and Maeder, L.A. (2000) The Prevalence of Calcified Carotid Artery Atheromas on the Panoramic Radiographs of Patients with Type 2 Diabetes Mellitus. Oral Surgery, Oral Medicine, Oral Pathology, Oral Radiology and Endodontics, 89, 420-424. http://dx.doi.org/10.1016/S1079-2104(00)70122-3

[21] Freymiller, E.G., Sung, E.C. and Friedlander, A.H. (2000) Detection of Radiation-Induced Cervical Atheromas by Panoramic Radiography. Oral Oncology, 36, 175-179. http://dx.doi.org/10.1016/S1368-8375(99)00072-X

[22] Friedlander, A.H. and Baker, J.D. (1994) Panoramic Radiography: An Aid in Detecting Patients at Risk of Cerebrovascular Accident. Journal of the American Dental Association, 125, 1598-1603.

[23] Friedlander, A.H. and Farman, A.G. (2007) Detection of Carotid Atheromas by Panoramic Radiography. Inside Dentistry, 3, 46-51.

[24] Ohba, T., Takata, Y., Ansai, T., Morimoto, Y., Tanaka, T., Kito, S., et al. (2003) Evaluation of Calcified Carotid Ar- 
tery Atheromas Detected by Panoramic Radiographs among 80-Year-Old. Oral Surgery, Oral Medicine, Oral Pathology, Oral Radiology and Endodontics, 96, 647-650. http://dx.doi.org/10.1016/j.tripleo.2003.07.001

[25] Carter, L.C., Haller, A.D., Nadarajah, V., Calamel, A.D. and Aguirre, A. (1997) Use of Panoramic Radiography among an Ambulatory Dental Population to Detect Patients at Risk of Stroke. Journal of the American Dental Association, 128, 977-984. http://dx.doi.org/10.14219/jada.archive.1997.0338

[26] Beckstrom, B.W., Horsley, S.H., Scheets, J.P., Khan, Z., Sliveria, A.M., et al. (2007) Correlation between Carotid Area Calcifications and Periodontitis: A Retrospective Study of Digital Panoramic Radiographic Findings in Pretreatment Cancer Patients. Oral Surgery, Oral Medicine, Oral Pathology, Oral Radiology and Endodontics, 103, 359-366.

[27] Friedlander, A.H., Eichstaedt, R.M., Friedlander, I.K. and Lambert, P.M. (1998) Detection of Radiation-Induced, Accelerated Atherosclerosis in Patients with Osteoradionecrosis by Panoramic Radiography. Journal of Oral and Maxillofacial Surgery, 56, 455-459. http://dx.doi.org/10.1016/S0278-2391(98)90712-1

[28] Joakimsen, O., Bonaa, K.H., Stensland-Bugge, E. and Jacobsen, B.K. (2000) Population-Based Study of Age at Menopause and Ultrasound Assessed Carotid Atherosclerosis: The Tromso Study. Journal of Clinical Epidemiology, 53, 525-530. http://dx.doi.org/10.1016/S0895-4356(99)00197-3

[29] Ravon, N.A., Hollender, L.G., McDonald, V. and Persson, G.R. (2003) Signs of Carotid Calcification from Dental Panoramic Radiographs Are in Agreement with Doppler Sonography Results. Journal of Clinical Periodontology, 30, 1084-1090. http://dx.doi.org/10.1046/j.0303-6979.2003.00427.x

[30] Sisman, Y., Ertas, E.T., Gokce, C., Menku, A., Ulker, M. and Akgunlu, F. (2007) The Prevalence of Carotid Artery Calcification on the Panoramic Radiographs in Cappadocia Region Population. European Journal of Dentistry, 1, 132 138.

[31] Johansson, E.P., Ahlqvist, J., Garoff, M., Karp, K., Jäghagen, E.L. and Wester, P. (2011) Ultrasound Screening for Asymptomatic Carotid Stenosis in Subjects with Calcifications in the Area of the Carotid Arteries on Panoramic Radiographs: A Cross-Sectional Study. BMC Cardiovascular Disorders, 11, 44. http://dx.doi.org/10.1186/1471-2261-11-44

[32] Friedlander, A.H., Tajima, T. and Garrett, N.R. (2011) Panoramic Radiographs of Head and Neck Cancer Patients Are Often Evidence of Carotid Artery Atherosclerotic Lesions: A Sign of High-Risk Comorbid Illness. Journal of Oral and Maxillofacial Surgery, 70, 1096-1101. http://dx.doi.org/10.1016/j.joms.2011.05.020

[33] Friedlander, A.H. and Friedlander, I.K. (1998) Identification of Stroke Prone Patients by Panoramic. Australian Dental Journal, 43, 51-54. http://dx.doi.org/10.1111/j.1834-7819.1998.tb00153.x

[34] Romano-Sousa, G.M., Krejcj, L., Medeiros, F.M., Graciosa-Filho, R.G., Martins, M.F., Guedes, V.N., et al. (2009) Diagnostic Agreement between Panoramic Radiographs and Color Doppler Images of Carotid Atheroma. Journal of Applied Oral Science, 17, 45-48.

[35] Christou, P., Leemann, B., Schimmel, M., Kiliaridis, S. and Müller, F. (2010) Carotid Artery Calcification in Ischemic Stroke Patients Detected in Standard Dental Panoramic Radiographs-A Preliminary Study. Advances in Medical Sciences, 55, 26-31. http://dx.doi.org/10.2478/v10039-010-0022-7

[36] Ezoddini Ardakani, F., Afkhami, M., Mohammadi, Z. and Sheikhha, M.H. (2007) Evaluating Calcified Carotid Artery Atheromas in Panoramic Radiographs of Patients with Type 2 Diabetes Mellitus. Oral Radiology, 23, 6-9. 
Scientific Research Publishing (SCIRP) is one of the largest Open Access journal publishers. It is currently publishing more than 200 open access, online, peer-reviewed journals covering a wide range of academic disciplines. SCIRP serves the worldwide academic communities and contributes to the progress and application of science with its publication.

Other selected journals from SCIRP are listed as below. Submit your manuscript to us via either submit@scirp.org or Online Submission Portal.
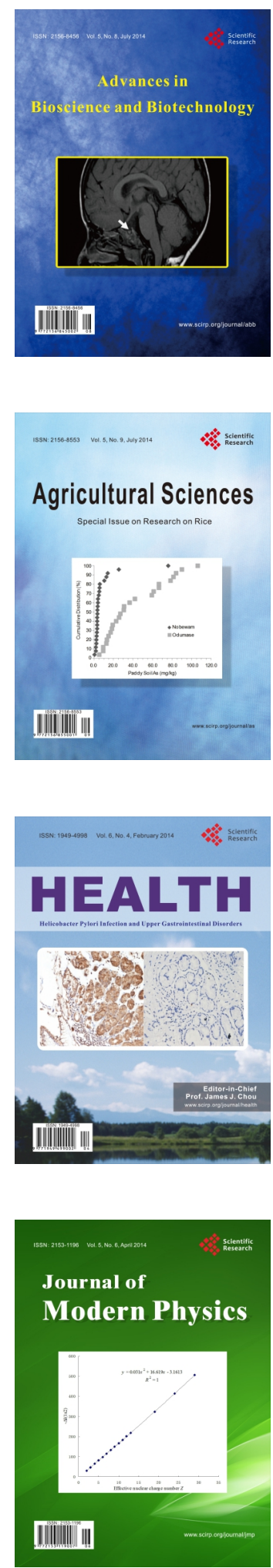
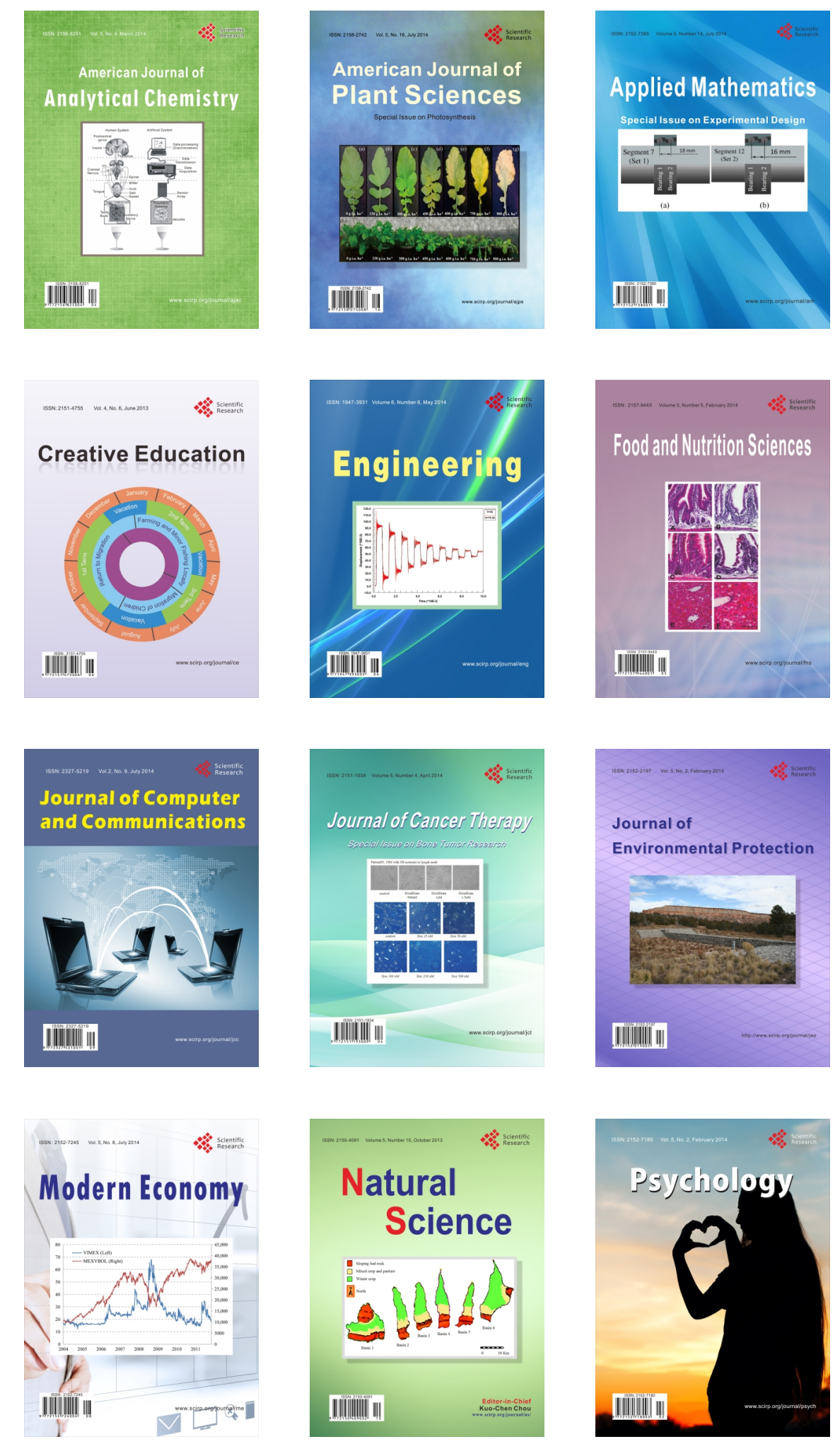